eISSN 2708-3004; pISSN: 2708-2997

www.joarps.org

https://doi.org/10.38211/joarps.2020.1.2.6

Crossref

\title{
EXPLORATION OF PREDATORY SPIDERS ON COTTON PESTS IN SPRAYED AND UN-SPRAYED COTTON FIELDS OF CCRI-SAKRAND-SINDH-PAKISTAN
}

\author{
Shah Nawaz Khuhro ${ }^{1 *}$, Khalid Abdullah ${ }^{2}$, Mohammad Farooque Hassan ${ }^{3}$, Muhammad Ali \\ Talpur $^{2}$, and Abdullah Keerio ${ }^{4}$ \\ ${ }^{1}$ Shaheed Zulfiquar Ali Bhutto Agricultural College Dokri, Sindh-Pakistan \\ ${ }^{2}$ Ministry of National Food Security \& Research, Government of Pakistan \\ ${ }^{3}$ Shaheed Benazir Bhutto University of Veterinary and Animal Sciences, Sakrand, Sindh. \\ Pakistan. \\ ${ }^{4}$ PCCC'Central Cotton Research Institute Sakrand, Sindh-Pakistan \\ *Corresponding Author: snkhuhro@gmail.com. \\ Article Received 04-04-2020, Revised 06-06-2020, Accepted 9-06-2020
}

\begin{abstract}
Explorations of predatory spiders were carried out from sprayed and unsprayed cotton crop grown at Central Cotton Research Institute Sakrand, Sindh-Pakistan during the period of MayOctober 2016 and 2017. During the research findings eight species of predatory spiders were explored and identified from cotton field which were Philodromus cespitum, Thanatus formicinus, Thyene imperialis, Oxyopes salticus, Cheiracanthium erraticum, Plexippus Paykulli, Lycosa tista and Pardosa birmanica. The activity of predatory spiders started in the month of May and June in the initial stage of cotton crop during the both years. The maximum spider population was noted in the months of July and August, when cotton crop was fully mature. The population of predatory spiders increased 61 in un-sprayed plot and 28 in sprayed in 2016 and 43 numbers of predatory spiders in un-sprayed plot and 22 in the sprayed plot during 2017. The maximum mean number of spiders was found to be 69 in un-sprayed plot and 36 in sprayed plot in 2016 as compared to 54 and 26 in 2017. Number of spiders were lesser in the month of September and October, the population of spiders decreased with the less population of sucking insect pests due to mature age of cotton crop in both plots in 2016 and 2017. There is a dire need to explore the insecticide effects on the predatory spiders of Pakistan and protection to keep the spiders safe from indiscriminate use of insecticides on cotton crop as they are bio-control agents and contribute their big part in the agriculture ecosystem, food chains and control of arthropods.
\end{abstract}

KeyWords: Population, Spiders; Cotton pests; Insecticides.

\section{Introduction}

Pakistan is main competitor in worldwide cotton sell with world's third major manufacturer of yarn and the second biggest exporter, the seventh major manufacturer of textile items and the third major exporter (ICAC, USA). Pakistan in the cotton and cotton goods, financial positions is nearly about $60 \%$ of it's in a foreign country income. However, in growing of cotton, the financial records are less than $10 \%$ of value-added in crop growing and Pakistan's nearly 2\% of
GDP. The wealth of our country is greatly dependent on cotton production and its derivatives (Bakhsh, 2009; Sial et al., 2014). Pakistan is amongst the leading producers of cotton, with big spinning ability in Asia region. Worldwide Pakistan makes 5\% to spinning ability following China and India. Currently, Pakistan has 1,221 ginning units, 472 spinning units and 425 additional little units to produce textile goods. Pakistan provides whole mention contributions at 
present provides about 55\% to the Pakistan's whole export (Memon, 2016). Spiders are poisonous, 40 species of spiders are probably noxious to humans, some spiders are greedy predators and carnivorous. The classification position of the spiders has been described the globally by (Platnick, 2004). Spiders are the included in the arachnids consists about 30 thousand species, 60 families dispersed globally (Sharma et al., 2010). Spiders are generally known as generalist bio-control agent and have a big power in the direction of the pattern of the population, particularly the food train and food net. Spiders play significant position as the bio-control agent, mostly the bio-control agent of arthropods and hence spiders supply to manage the insects position (Borror et al., 1989; Kostanjšek et al., 2015). Predatory spiders are successful biocontrol agents; to eat numerous harmful arthropods in agro-ecosystem (Hodge, 1999). Spider society having various natural places may jointly play a significant contribution in decreasing the populations of harmful arthropods (Ghafoor, 2002). Predatory

\section{Material and Methods}

The experiment was kept in the cotton fields of Pakistan Central Cotton Research Institute Sakrand, Shaheed Benazirabad, during 2016 and 2017 on the explorations of predatory spiders on cotton pests in sprayed and unsprayed cotton fields. The commercial varieties as CRIS-134 and CRIS-342 were sown on the 2 acres area. Sucking insect pests population was documented from the cotton plant counting with twenty selected leaves from the top, middle and bottom portion of the cotton plant in each plot with the recording of spiders' per plant population. When the population of sucking insect pests reached on Economic threshold level (ETL), the spray was applied for the controlling of sucking insect pests. After 72 hours application of spray population of spiders was recorded to note the effects of pesticides on spider population. The recording of spider spiders' groups are one of the most abundant in the terrestrial ecosystems, so prey on insects, several new insects and participate significant job in pest management and in the worldwide more than 3500 species of spiders have been recognized (Ghavami et al., 2007). Spiders are the carnivorous arthropods, eat a huge amount of preys and do not injure the plants. Spiders have unique habitation and live in almost the entire surroundings. Spiders provide as buffers that bound the first exponential increase of prey populations (Rajeswaran et al., 2005). In Pakistan on the agricultural crops and vegetables insect pest management by insecticides has un-balanced the ecosystem and damaged the bio-control agents of harmful insect pests of crops. Other side, due to random application of insecticides, the arthropods pests created the resistance against several insecticides. The present study composed a challenge to set up and evaluate the population buildup and abundance of spiders in the cotton fields of sprayed and unsprayed against the serious cotton pests in Pakistan

populations noted weekly basis with the general observations until the $2^{\text {nd }}$ spray. One acre crop was treated with different insecticides with two times in both years and another one acre plot was not treated with any type of insecticides throughout the experimental period. During the experiment recommended all agronomic cultural practices i.e., inter culturing fertilizer, and irrigations were used according to the condition of the crop. One plot of Cotton crop was sprayed with pesticides, two times when the population reached the economic injury level. Initially, Amamectin, Lufenuran and Bifenthrin in 2016 and Nitenpyrum, Bifenthrin and Dimethoate in 2017 were applied on cotton crop against sucking and bollworm complex. Spider numbers was checked carefully from entire plant of cotton crop. Observation data were noted from both 
un-sprayed and sprayed cotton crops from May to October 2016 and 2017 on every week at 7 to 10 a.m. For the identification of various species were collected with the help of hand nets $(14 \mathrm{~cm}$ dia.) whereas, small species of spiders were collected with the help of aspirator. All Collected specimens were kept for identification and preservation purpose to the Bio-Control laboratory of the CCRISakrand.

\section{Results and Discussion}

Table: 1 List of Predatory spiders recorded and identified from Cotton crop during 2016 and 2017

\begin{tabular}{|l|l|l|}
\hline S.No & Scientific Name & Family \\
\hline 1. & Philodromus cespitum & Philodromidae \\
\hline 2. & Thanatus formicinus & Philodromidae \\
\hline 3. & Thyene imperialis (Jumping) & Salticidae \\
\hline 4. & Oxyopes salticus & Oxyopidae \\
\hline 5. & Cheiracanthium erraticum & Cheiracanthiidae \\
\hline 6. & Plexippus Paykulli & Salticidae \\
\hline 7. & Lycosa tista & Lysosidae \\
\hline 8. & Pardosa birmanica (Wolf spider) & Lycosidae \\
\hline
\end{tabular}

The results in (fig. 1 and 2) shows the activity of spiders started in the month of May with the attack of whitefly and jassids, when the cotton crop was on initial stage. The spider population was started in both plots from May during 2016 with 18 relative numbers of spiders in sprayed plot and 38 numbers in unsprayed plot. Similarly, the population was recorded in the month of May during 2017, with 12 numbers of spiders in sprayed plot and 29 numbers of spiders in un-sprayed plot. Gradually population of spiders increased with the time and reached in the month of June during 2016 with 22 numbers of spiders in the sprayed plot and 45 numbers of spiders in unsprayed plot. Similarly, in the month of June, the number of spiders was found 16 in sprayed
The data in Table- 1 showed that eight species of predatory spiders were recorded in both unsprayed and sprayed cotton fields. These species identified were Philodromus cespitum, Thanatus formicinus, Thyene imperialis (Jumping), Oxyopes salticus, Cheiracanthium erraticum, Plexippus Paykulli, Lycosa tista and Pardosa birmanica. All the spiders were kept and preserved in the Bio-control laboratory of CCRI-Sakrand for display the grower's information and awareness. 


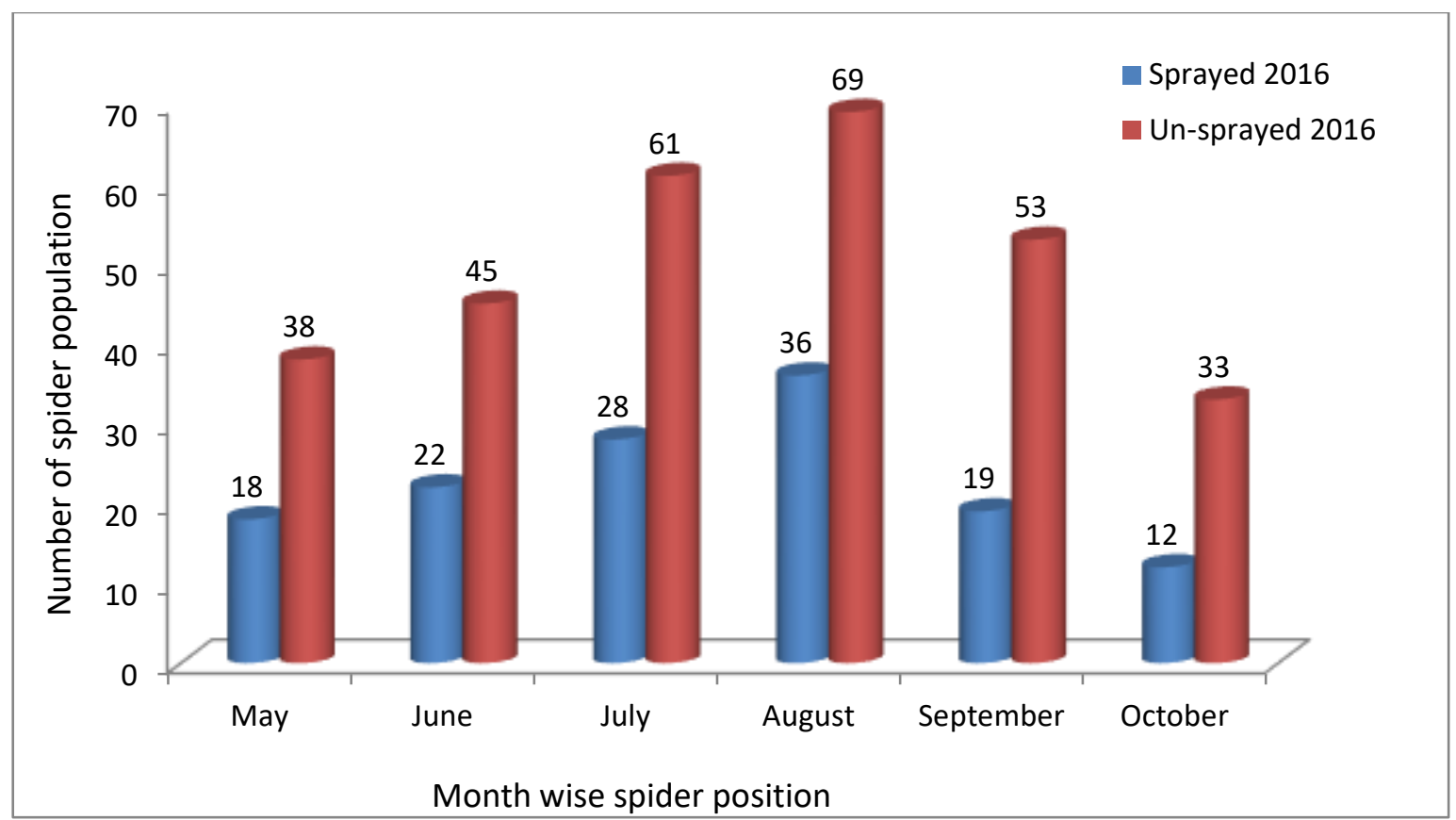

Figure:1 Seasonal Per Plant Population Of Spiders in sprayed and un-sprayed Cotton plot From May To October During 2016

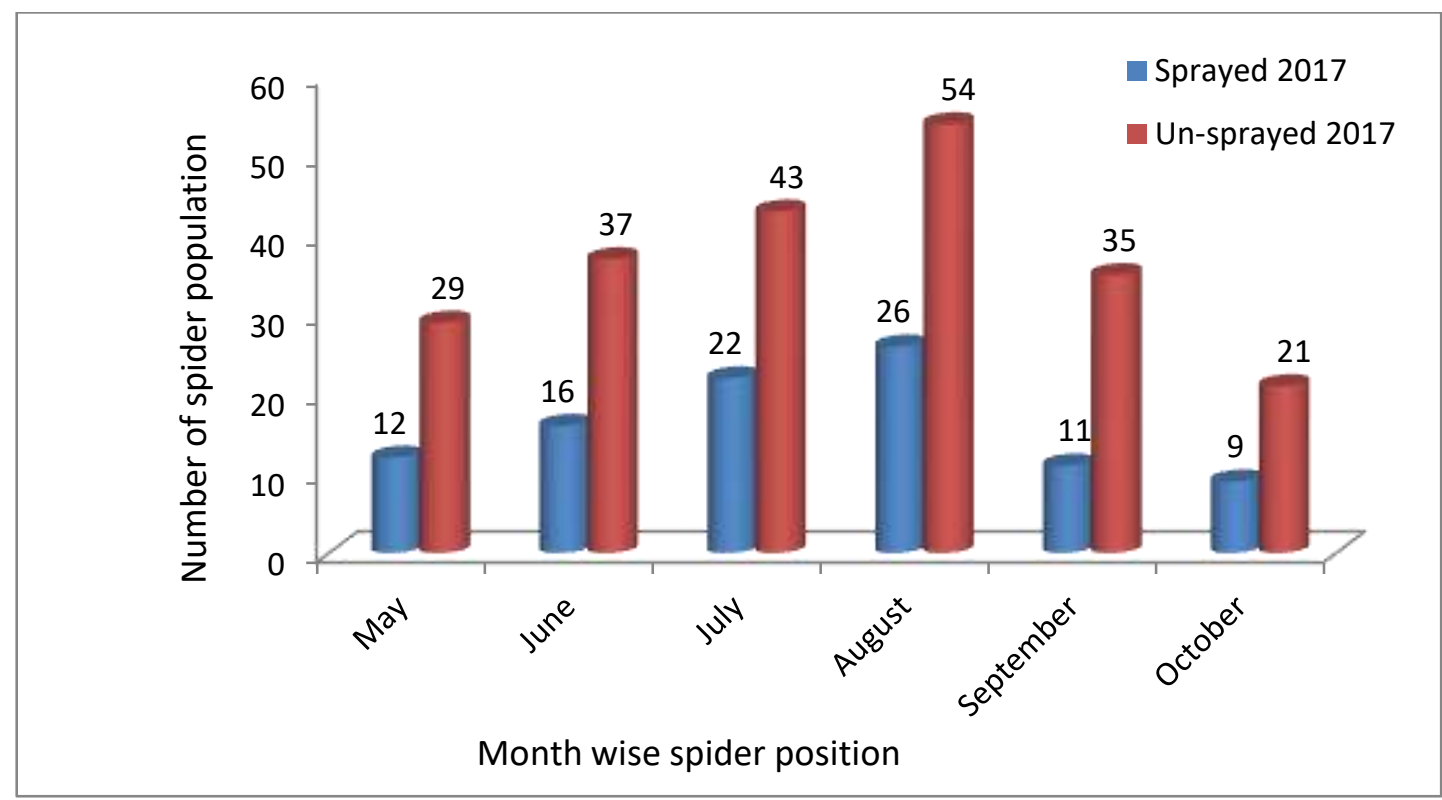

Figure:2 Seasonal Per Plant Population Of Spiders in sprayed and un-sprayed Cotton plot From May To October During 2017

The further results indicated that maximum population of predatory spiders was 79 in the month of August, in un-sprayed plot and 36 numbers of spiders in sprayed plot during 20016 and in the same way 54 numbers of spiders was found in un-sprayed plots and 26 numbers of spiders was recorded in unsprayed plot during 2017. The low numbers of spiders were found in September and October months due to low numbers of arthropods on 
cotton crop and may also be due to old age of cotton plants. Similarly, in the month of September, the more relative numbers of spiders 53 was in un-sprayed plot and 19 numbers of spiders in sprayed plot during 2016 and in the same way more numbers of spiders 35 were recorded in un-sprayed plots as compared to 11 numbers of spiders were recorded in sprayed cotton plot during 2017. Finally, in the month of October when the $2^{\text {nd }}$ picking is completed the population was decreased due to the less population of sucking insects and also cotton crop was $85 \%$ picked or harvested. The spider population recorded with 21 in un-sprayed cotton plot and 09 numbers of spiders were recorded in sprayed cotton plot and 33 numbers of spiders in un-sprayed cotton plot and 12 numbers of spiders in sprayed cotton plot during 2017. Comparatively, the maximum mean numbers of all spiders' species were recorded in the unsprayed cotton plot as compared to sprayed cotton plot. Present studies on explorations of predatory spiders on cotton pests in sprayed and unsprayed cotton fields indicated that total eight species of spiders were recorded and kept in Entomology Museum of CCRISakrand for record and awareness to the cotton growers. Overall results show that when the spray was done the population of spiders reduced as earlier evaluated and mentioned by Xingyuan et al. (2004), that the insecticides application reduced the population of spiders which are bio-control agents of cotton insects in the cotton crop. Furthermore, data indicated that more number of friendly spiders was found in cotton crop in the un-sprayed plot and also studies revealed that less numbers of predatory spiders found due to application of pesticides in sprayed cotton plot. The Study showed that maximum number of sucking insects observed on lush

\section{References}

Bell, J. R., Wheater, C. P., \& Cullen, W. R. (2001). The implications of grassland and heathland management for the green cotton during July-August and maximum number of predatory spiders was also present during the July and August months. Our study finds were agreed with that statement that spiders are usually directly associated to the characters of the plant composition. The spiders makes the net is thoroughly associated to the structural design of the vegetation. Many research results mentioned the effect of plant diversity on habitat structure and microclimatic characteristics (Bell et al., 2001; Schuldt et al., 2008). Ghafoor (2002) reported in their research that after the application of spray in the field of cotton crop of Faisalabad Punjab more than 16 species of spiders were observed during the months of August to December. Further from the treated cotton fields sum of 64 specimens of spiders were collected. Further data shows that during middle in maturity stage of cotton crop, the more numbers of spiders were recorded. Our results are also in agreement with the findings of Yong et al. (2006) who reported that the greater prosperity period of predatory spiders was in vegetative and reproductive growth stage of cotton. Whereas, Mushtaque et al. (2003) reported that in cotton maximum number of spiders were recorded in July, species richness was greater in July species diversity was most pronounced in September and October. Our results were meet the results with the El-Heneidy et al. (1996) who indicated in survey study that more numbers of spiders were recorded when the cotton crop was in middle stage and more numbers of predatory spiders were in the month of August. Dippenaar et al. (1999) reported that spiders contribute a vital job in keeping pests at endemic levels and to stop the any occurrence of arthropods on any crop.

conservation of spider communities: a review. Journal of zoology, 255(3): 377-387. 
Business Recorder. (2019). https://www.brecorder.com/2019/10/1 $5 / 530864 /$ countrys-current cottonwoes/

Bakhsh, A., Rao, A. Q., Shahid, A. A., Husnain, T., \& Riazuddin, S. (2009). Insect resistance and risk assessment studies in advance lines of Bt cotton harboring Cry1Ac and Cry2A genes. American-Eurasian Journal of Agricultural and Environmental Sciences, 6(1): 1-11.

Borror, D. J., Triplehorn, C. A., \& Johnson, N. F. (1989). An introduction to the study of insects (No. Ed. 6). Saunders college publishing.

Ghafoor, A. 2002. Taxonomic and some ecological studies of the cursorial spiders of cotton fields at Faisalabad (Pakistan). Ph.D Thesis. 275p.

Hodge, M. A. (1999). The implications of intraguild predation for the role of spiders in biological control. Journal of Arachnology, 351-362.

https://www.icac.org/DataPortal/DataPortal/?

Pakistan Report on update of Cotton in Pakistan.

Memon, R. A., Bhatti, G. R., Khalid, S., Mallah, A., \& Ahmed, S. (2013). Illustrated weed flora of wheat crop of Khairpur District, Sindh. Pak. J. Bot, 45(1): 39-47.

Kostanjšek, R., Kuralt, Ž. S., \& N-Velkavrh, M. (2015). Comparison of spider diversity in two temperate forests by a rapid survey and its potential in nature conservation studies. Applied ecology and environmental research, 13(3): 693-708.

Memon, Noor Ahmed. (2016). Spinning Review. https://www.ptj.com.pk/Web2016/02-2016/PDF-February2016/Spinning-Dr-Noor.pdf

Mushtaq, S., Beg, M. A., \& Aziz, S. (2003). Biodiversity and temporal variations in the abundance of cursorial spiders of a cotton field at Faisalabad. Pakistan journal of zoology, 35(2): 125-131.

Platnick NJ. (2004). The World Spider Catalog, Version 5.0. American Museum of Natural History Online at, Http://Research.Amnh.Org/Entomolog y/Spiders/Catalog/I ndex.Html

Schuldt, A., Fahrenholz, N., Brauns, M., Migge-Kleian, S., Platner, C., \& Schaefer, M. (2008). Communities of ground-living spiders in deciduous forests: Does tree species diversity matter? Biodiversity and conservation, 17(5): 1267-1284.

Turnbull, A. L. (1973). Ecology of the true spiders (Araneomorphae). Annual review of entomology, 18(1): 305-348.

Sharma, S., Vyas, A., \& Sharma, R. (2010). Diversity and abundance of spider fauna of Narmada river at Rajghat (Barwani) (Madhya Pradesh) India. Researcher, 2(11): 1-5.

Sial, K. B., Kalhoro, A. D., Ahsan, M. Z., Mojidano, M. S., Soomro, A. W., Hashmi, R. Q., \& Keerio, A. (2014). Performance of Different Upland Cotton Varieties under the Climatic Condition of Central Zone of Sindh. American-Eurasian J. Agric. Environ. Sci, 14: 1447-1449.

Men, X., Ge, F., Edwards, C. A., \& Yardim, E. N. (2004). Influence of pesticide applications on pest and predatory arthropods associated with transgenic Bt cotton and non-transgenic cotton plants. Phytoparasitica, 32(3): 246254. 